Research Article

\title{
Emergency Transportation Problem Based on Single-Valued Neutrosophic Set
}

\author{
Lin $\operatorname{Lu} \mathbb{D}^{1}$ and Xiaochun Luo $\mathbb{D}^{1,2}$ \\ ${ }^{1}$ College of Economics and Management, Guangxi Normal University, Guilin, China \\ ${ }^{2}$ College of Economics and Management, Nanjing University of Aeronautics and Astronautics, Nanjing, China
}

Correspondence should be addressed to Xiaochun Luo; 57747278@qq.com

Received 13 July 2019; Revised 12 February 2020; Accepted 24 March 2020; Published 21 April 2020

Academic Editor: Giancarlo Consolo

Copyright (c) 2020 Lin Lu and Xiaochun Luo. This is an open access article distributed under the Creative Commons Attribution License, which permits unrestricted use, distribution, and reproduction in any medium, provided the original work is properly cited.

\begin{abstract}
Emergency events are full of large number of uncertain information. The existence of these uncertain information leads to less research on emergency logistics involving transshipment scenarios. In this paper, a new emergency transport model is proposed, which simulates the scenario of emergency transport from the logistics center to each disaster site and between each disaster site. The single-valued neutrosophic set (SVNS) is applied to transform the emergency transshipment problem into a multiattribute decision-making problem in ambiguous and uncertain environments. Technology for order preference by similarity to ideal solution (TOPSIS) is extended to the single-valued neutrosophic environment to rank and optimize the alternative transshipment routes. Firstly, the attribute weight is determined by using the entropy weight method; secondly, the scoring function of the singlevalued neutrosophic fuzzy number is defined; thirdly, the TOPSIS method is used to rank the decision-making; finally, the feasibility and rationality of the proposed method are verified by an emergency operation example.
\end{abstract}

\section{Introduction}

Unexpected events will result in huge losses, most of these losses are because the event of emergency logistics has not been carried out in place. How to complete the scheduling scheme and make the emergency resources arrive at the emergency location in the shortest time under the unpredictable situation is the key to consider. The existing emergency distribution literature mainly focuses on the emergency logistics distribution center delivering emergency materials to the disaster-affected areas. However, due to the unexpected events and uncertainties, it will inevitably lead to the shortage of material supply during the disaster. After the disaster, a large number of materials are needed in a short period of time, and secondary disasters may occur on the way of transportation, which makes it more difficult to realize the emergency rescue logistics. It is an urgent task to develop and strengthen the emergency logistics construction. So far, the development of foreign emergency logistics and distribution system is basically mature, and some countries have set up a special emergency logistics agency, such as Canadian emergency logistics preparation office, New Zealand Ministry of civil defense and emergency logistics management, the Australian emergency management agency, the Swiss National emergency management center transport logistics department, Russian emergency situations ministry of transport logistics department, and American California transport emergency office. These emergency logistics systems not only have existing institution comprehensive emergency logistics agencies but also have all sectors of emergency management agencies of the logistics, various emergency management agencies interrelated and support each other, in a huge emergency logistics transport system. Özdamar et al. [1] studied the emergency logistics plan after the disaster and established the emergency logistics distribution model, which combines waterway, railway, and highway. Hale and Moberg [2] established a quantitative model, which studied the selection of emergency logistics supply nodes according to the storage of emergency materials at nodes. Miller-Hooks and 
Mahmassani [3] studied algorithms that were presented for determining the least possible time paths for all origins to a single destination in networks where the arc weights were discrete random variables whose probability distribution functions vary with time. Chang et al. [4] took the flood in Taipei as the background, introduced scenarios and probability of scenarios to describe the uncertainty of various needs, and established a stochastic programming model to solve the emergency resource scheduling problem. Rathi et al. [5] proposed mathematical models for a macrolevel analysis of a supply logistics problem that involved the allocation of a limited number of transport resources (assets) towards the shipment of cargo and personnel (movement requirements) between many origins and destinations within prescribed time windows. The problem had been modeled by three linear programming formulations. Rahman and Smith [6] reviewed the use of location-allocation models in health service development planning in the developing nations and examined the suitability of these methods for designing healthcare systems. Fiedrich et al. [7] believed the main goal of the initial search-and-rescue period after strong earthquakes was to minimize the total number of fatalities. They attributed this problem to find the best allocation of available resources to the business area and proposed a dynamic optimization model that used detailed descriptions of the operational areas and of the available resources to calculate the resource performance and efficiency for different tasks related to the response. Yi and Özdamar [8] proposed a mixed integer multicommodity network flow model that treated vehicles as integer commodity flows rather than binary variables. This resulted in a more compact formulation whose output was processed to extract a detailed vehicle route and load instruction sheet. There are many kinds of literature studies on the location of emergency supplies, such as Balcik and Beamon [9] who developed a model that determined the number and locations of distribution centers in a relief network and the amount of relief supplies to be stocked at each distribution center to meet the needs of people affected by the disasters. The model, which was a variant of the maximal covering location model, integrated facility location and inventory decisions, considered multiple item types, and captured budgetary constraints and capacity restrictions. Rawls and Turnquist [10] also developed an emergency response planning tool that determined the location and quantities of various types of emergency supplied to be prepositioned, under uncertainty about if, or where, a natural disaster would occur. Artificial intelligence algorithm had also been applied in emergency logistics scheduling $[11,12]$.

China is one of the first countries in the world to carry out the theme disaster emergency management in emergency logistics and distribution system research area, and there are many scientific research institutions and experts and scholars from colleges and universities who conducted in-depth research and achieved many results. Yao [13] analyzed the characteristics of disaster reduction management in ancient China and the progress, advantages, and disadvantages of modern disaster reduction management. On this basis, the development direction of disaster reduction management in the future was discussed. The importance of professional management functions and institutions, including the organization and management of emergency logistics systems, was put forward to enhance the unity of government management. Sun et al. [14] developed a multiobjective optimization model based on robust optimization theory aiming at minimizing the longest distribution routine time and the total logistic system cost which considered the risk of road congestion, the risk of road damage, the risk of the road complexity, and the demand uncertainty of relief commodities.

Zhu et al. [15] studied the evaluation method based on CI-TOPSIS fuzzy multicriteria group strategy, which was proposed to assess the cascading failure invulnerability of emergency logistics network in order to evaluate the dynamic network topology under emergent even. From the existing literature, the domestic scholars on the characteristics of emergency logistics, security mechanisms, forms of organization and emergency logistics center construction, emergency supplies reserves and scheduling, transportation, and emergency supplies distribution issues conducted extensive research made a series of theoretical research results. As pioneering research in this relatively new field of emergency logistics, these achievements not only played a good indication of the effect of research but also exposed some shortcomings, especially the study of the transport and distribution of emergency logistics is still relatively small. Emergency events are full of large number of uncertain information. The existence of these uncertain information leads to less research on emergency logistics involving transshipment scenarios. In order to deal with this uncertain information, Smarandache [16-20] introduced independent uncertainties and put forward the concept of neutrosophic set considering three parameters: the degree of truth, the degree of uncertainty, and the degree of distortion for the first time. Uncertainty is clearly quantified in the neutrosophic set, and the real, uncertain, and distortion components are irrelevant. This assumption can help decision makers express their opinions more accurately and in detail. Wang et al. [21] and Ye [22] defined the single-valued neutrosophic set and its aggregator, and Ye [23] defined the crossentropy and its correlation coefficients of the singlevalued neutrosophic set, which enriched and developed the relevant theories of the neutrosophic set. Recently, many articles on TOPSIS [24-34] and tool [35-38] research appeared in the neutrosophic set field.

Because the unexpected and uncertain nature of emergencies will inevitably lead to the shortage of disaster relief materials in the process of disaster relief, a large number of materials will be needed in a short time after the occurrence of disasters, and secondary disasters such as road breakage may occur during the transportation of materials, which makes the emergency logistics for disaster relief more difficult to achieve. It is an urgent matter to develop and improve emergency logistics. In view of this, in order to solve the problem of shortage of disaster relief materials, according to the requirement of rapid distribution of emergencies, this paper, based on the traditional vertical distribution of emergency logistics centers to various 
disaster-stricken areas, turns the operation into a feasible and effective means of emergency logistics distribution system. The model simulates the emergency transshipment of logistics centers to various disaster-stricken areas and between disaster-stricken areas. The scenario reflects the development of the disaster situation in the system and its demand for disaster relief materials in a certain period of time. This emergency transportation problem is transformed into a multiattribute decision-making problem under ambiguous and uncertain environments by using the singlevalued neutrosophic set, and then TOPSIS is extended to the single-valued midintelligence environment to determine alternative transportation routes by ranking.

\section{Methods}

\subsection{The Basic Concept of Single-Valued Neutrosophic Set} (SVNS)

Definition 1 (see [39]). Let $x$ be an element in a finite set $X$, and then a single-valued neutrosophic set $A$ in $X$ is characterized by a truth membership function $T_{A}(X)$, an indeterminacy membership function $I_{A}(X)$, and a falsity membership function $F_{A}(X)$, which can be denoted as

$$
A=\left\{\left\langle x, T_{A}(x), I_{A}(x), F_{A}(x)\right\rangle \mid x \in X\right\} .
$$

The functions $T_{A}(x), I_{A}(x)$, and $F_{A}(x)$ are real standard or nonstandard subsets of $] 0^{-}, 1^{+}[$, and there is no restriction on the sum of $T_{A}(x), I_{A}(x)$, and $F_{A}(x)$, i.e., $0^{-} \leq T_{A}(x)+I_{A}(x)+F_{A}(x) \leq 3^{+}$.

Definition 2 (see [16]). Let $A=\left\{\left\langle x, T_{A}(x), I_{A}(x), F_{A}(x)\right\rangle \mid\right.$ $x \in X\}$ and $B=\left\{\left\langle x, T_{B}(x), I_{B}(x), F_{B}(x)\right\rangle \mid x \in X\right\}$ be single-valued neutrosophic set, and the complement of neutrosophic set $A$ is denoted by $A^{c}$ and can be defined by

$$
A^{c}=\left(1-T_{A}, 1-I_{A}, 1-F_{A}\right) \text {. }
$$

Definition 3 (see [39]). According to Majumder and Samanta [40], the entropy measure of a SVNS $A=$ $\left\{\left\langle x, T_{A}(x), I_{A}(x), F_{A}(x)\right\rangle \mid x \in X\right\}$ is expressed in

$$
E(A)=1-\frac{1}{n} \sum_{i=1}^{m}\left(T_{A}\left(x_{i}\right)+F_{A}\left(x_{i}\right)\right)\left|I_{A}\left(x_{i}\right)-I_{A^{C}}\left(x_{i}\right)\right| \text {. }
$$

In order to obtain the entropy value $E_{j}$ of the $j$ th attribute $C_{j}(j=1,2, \ldots, n)$, equation (3) can be written as

$$
E_{j}=1-\frac{1}{n} \sum_{i=1}^{m}\left(T_{i j}\left(x_{i}\right)+F_{i j}\left(x_{i}\right)\right)\left|I_{i j}\left(x_{i}\right)-I_{i j}^{C}\left(x_{i}\right)\right|, \quad i=1,2, \ldots, m ; j=1,2, \ldots, m .
$$

It is also noticed that $E_{j} \in[0,1]$. Due to Hwang and Yoon [41] and Wang and Zhang [42], the entropy weight of the $j$ th attibute $C_{j}$ is expressed in

$$
\omega_{j}=\frac{1-E_{j}}{\sum_{j=1}^{n} 1-E_{j}} .
$$

Definition 4 (see [43]). Let $a=\left\langle t_{a}, i_{a}, f_{a}\right\rangle$ to be a singlevalued fuzzy number, and the scoring function of $a$ is denoted by $S_{(a)}$ and can defined by

$$
S_{(a)}=\frac{t_{a}-i_{a}-f_{a}}{3}
$$

Definition 5 (see [44]). Let $A=\sum_{i=1}^{n}\left(x_{i} /\left\langle t_{A}\left(x_{i}\right)\right.\right.$, $\left.\left.i_{A}\left(x_{i}\right), f_{A}\left(x_{i}\right)\right\rangle\right)$ and $B=\sum_{i=1}^{n}\left(x_{i} /\left\langle t_{B}\left(x_{i}\right), i_{B}\left(x_{i}\right), f_{B}\left(x_{i}\right)\right\rangle\right)$ be single-valued neutrosophic sets.

The Euclidean distance between single-valued neutrosophic set $A$ and single-valued neutrosophic set $B$ is expressed in

$$
q(A, B)=\sqrt{\sum_{i=1}^{n}\left\{\left(t_{A}\left(x_{i}\right)-t_{B}\left(x_{i}\right)\right)^{2}+\left(i_{A}\left(x_{i}\right)-i_{B}\left(x_{i}\right)\right)^{2}+\left(f_{A}\left(x_{i}\right)-f_{B}\left(x_{i}\right)\right)^{2}\right\}} .
$$

The positive ideal solution $A^{*}=\left(d_{1}^{*}, d_{2}^{*}, \ldots, d_{n}^{*}\right)$, in which, $d_{j}^{*}=\max _{i}\left\{d_{i j}\right\}$.

The negative ideal solution $A^{-*}=\left(d_{1}^{-*}, d_{2}^{-*}, \ldots, d_{n}^{-*}\right)$, in which, $d_{j}^{-*}=\max _{i}\left\{d_{j}^{-*}\right\}$.
The distance from alternative $A_{i}$ to ideal solution $A^{*}$ is expressed in

$$
d_{j}^{*}=\sqrt{\sum_{j=1}^{n}\left[\omega_{j} q_{k}\left(d_{i j}-d_{j}^{*}\right)\right]}, \quad i=1,2, \ldots, n ; j=1,2, \ldots, n ; k=1,2, \ldots, n .
$$


The distance from alternative $A_{i}$ to negative ideal solution $A^{-*}$ is expressed in

$$
d_{j}^{-*}=\sqrt{\sum_{j=1}^{n}\left[\omega_{j} q_{k}\left(d_{i j}-d_{j}^{-*}\right)\right]}, \quad i=1,2, \ldots, n ; j=1,2, \ldots, n ; k=1,2, \ldots, n
$$
in

The comprehensive distance of each scheme is expressed

$$
G\left(A_{i}\right)=\frac{d\left(A_{1}, A^{-*}\right)}{d\left(A_{1}, A^{-*}\right)+d\left(A_{1}, A^{*}\right)}
$$

2.2. Emergency Delivery Model. Emergency logistics and transport are to meet some of the needs for emergency dispatching goods between different agencies at the same level as the supply chain carried out. The logistics network of mutual support peer transfer cargo between nodes in the study is called a lateral transport policy. It requires the implementation of the points shared between each of the affected disaster supplies and transport integration through the coordination point affected supplies to create a system to cover the entire pool of inventory, and maximize system to meet the needs of disaster supplies by improving each affected point service levels to reduce the risk. Thus, to achieve a vertical supply chain integration and horizontal integration of the affected point material combined so that the emergency distribution system to an uncertain environment has stronger adaptability.

Graph theory emergency logistics and distribution problems will be described as follows: $N=(V, K, R, T$, $S, U, P)$. The model indicates the network of emergency logistics distribution. $V$ represents the set of nodes in the network (virtual source point $o$, intermediate node distribution center $K_{1}, K_{2}, \ldots, K_{m}$, and demand points $R_{1}, R_{2}$, $\left.\ldots, R_{n}\right)$. $K$ represents the set of arcs of the network $\{(i, j) / i, j \in V, i \neq j\}$ and $T, S, U$, and $P$ represent the transport time set of each arc in the network $\left\{T_{i j} / i, j \in A\right\}$, unit transportation fee collection $\left\{S_{i j} / i, j \in A\right\}$, capacity of the collection $\left\{U_{i j} / i, j \in A\right\}$ and traffic collection $\left\{P_{i j} / i\right.$, $j \in A\}$, respectively. Each parameter calibration model is on its network.

The arc parameter $o$ from a virtual source point to the distribution center $K_{1}, K_{2}, \ldots, K_{m}$ is the transit time, the unit cost of each arc is 0 , and the capacities are $k_{1}, k_{2}, \ldots, k_{m}$.

The arc parameter from the distribution center node $K_{1}, K_{2}, \ldots, K_{m}$ to the demand points $R_{1}, R_{2}, \ldots, R_{n}$ is that the transportation time, unit cost, capacity, and flow on each arc are, respectively, $T_{i j}, S_{i j}, U_{i j}$, and $P_{i j}$.

In this way, the problem of emergency logistics allocation is transformed into a multiattribute decision-making problem in the environment of fuzziness and uncertainty.

\section{Example Analysis}

After a major disaster in an area, $K_{1}$ (national materials reserve warehouse) and $R_{1}$ (provincial materials reserve warehouse) send emergency supplies to seven disaster sites $1,4,5,7,8,10$, and 11 in the shortest possible time. According to the actual situation of the region, based on the idea of system theory and random network theory, the specific situation after the region affected and $K_{1}$ and $R_{1}$ materials reserve base of emergency stockpile to each disaster sites for emergency delivery, but due to the disaster site 7 there is an emergency, original distribution roads impassable and disaster situation deteriorate further, and the disaster sites 4, 8, and 11 transshipment goods and materials, to emergency rescue of the disaster site 7 , can build emergency drop shipping process of GERT random network model diagram (see Figure 1), in which the meaning of the activities is as shown in Table 1.

Four emergency transfer routes can be constructed from Figure 1 and Table 1:

$$
\begin{aligned}
& A_{1}(1 \longrightarrow 7): K_{1} \longrightarrow 1 \longrightarrow 2 \longrightarrow 3 \longrightarrow 4 \longrightarrow 7, \\
& A_{2}(3 \longrightarrow 7): K_{1} \longrightarrow R_{1} \longrightarrow 5 \longrightarrow 8 \longrightarrow 7, \\
& A_{3}(4 \longrightarrow 7): K_{1} \longrightarrow R_{1} \longrightarrow 8 \longrightarrow 7, \\
& A_{4}(5 \longrightarrow 7): K_{1} \longrightarrow R_{1} \longrightarrow 11 \longrightarrow 7 .
\end{aligned}
$$

According to the characteristics of emergency transportation, the construction attributes are, respectively, $\left\{C_{1}, C_{2}, C_{3}, C_{4}\right\}$. Among them, $C_{1}$ is transport time, $C_{2}$ is unit transport costs, $C_{3}$ its capacity, and $C_{4}$ is flow.

By inquiring the persons in charge of road traffic and emergency transshipment in this area, the result of the investigation $d_{i j}=\langle t, i, f\rangle$ of a standard $C_{j}$ of an emergency transit route $A_{i}$ is a single-valued neutrosophic set. Among them, $t$ is the degree of truth, $i$ is the degree of uncertainty, and $f$ is the degree of distortion; $t, i, f \in[0,1]$.

The details are shown in Table 2.

\section{Results}

Step 1. Calculate weight based on entropy weight method. According to formulas (3)-(5), the calculation results are as follows: 


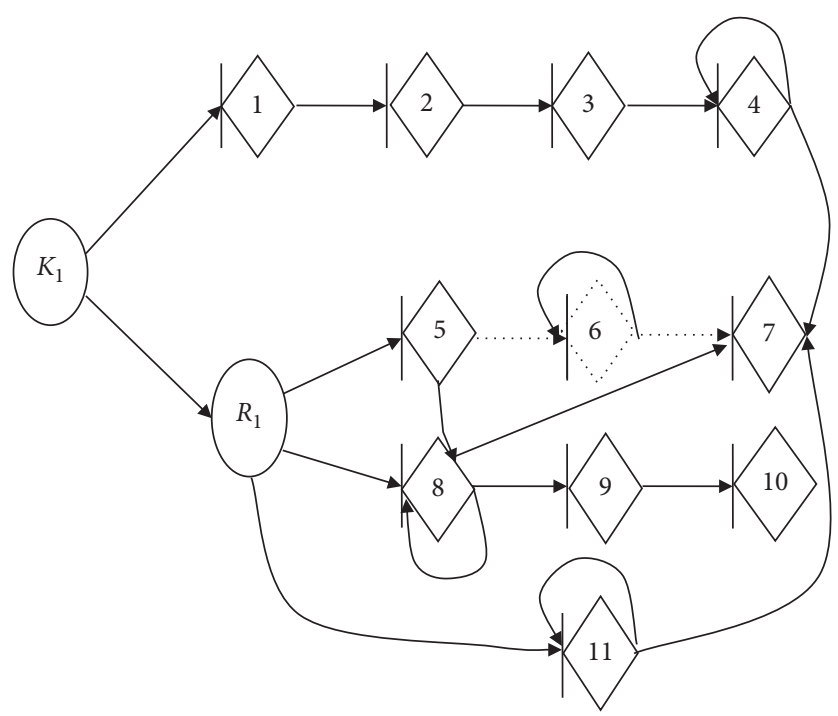

FIGURE 1: Network model of emergency transshipment and distribution from each disaster site to disaster point 7.

TABLE 1: The meaning of all the activities of the random network of emergency transport and distribution of each disaster point to the disaster point 7 .

\begin{tabular}{|c|c|}
\hline Activity & Activity description \\
\hline$\left(K_{1}, 1\right)$ & National materials reserve warehouse $K_{1}$ will fill up the first convoy \\
\hline$(1,2)$ & $\begin{array}{l}\text { The first convoy will unload the needed materials at the disaster point } 1 \text { and continue to deliver to the disaster point } 4 \text { (via the } \\
\text { road node } 2 \text { ) }\end{array}$ \\
\hline$(2,3)$ & The first convoy will deliver to the disaster point 4 via the road node point 2 (via the road node 3 ) \\
\hline & \\
\hline & \\
\hline$(4$ & The first convoy passed through the disaster point 4 \\
\hline$\left(K_{1}, R_{1}\right)$ & $\begin{array}{c}\text { National materials reserve warehouse } K_{1} \text { will fill up the second convoy and distribute it to the provincial materials reserve } \\
\text { warehouse } R_{1}\end{array}$ \\
\hline$\left(R_{1}, 5\right)$ & $\begin{array}{l}\text { The second convoy will unload the needed materials at prov } \\
\text { disa }\end{array}$ \\
\hline$(5,6)$ & $\begin{array}{c}\text { The second convoy will unload the needed materials at the disaster point } 5 \text { and con } \\
\text { node } 6 \text { ) }\end{array}$ \\
\hline$(5,8)$ & $\begin{array}{r}\text { On the road leading to road node } 6 \text {, the second convoy encou } \\
\text { disa }\end{array}$ \\
\hline$(5,7$ & \\
\hline$\left(R_{1}\right.$ & eas \\
\hline$(8,8)$ & $\begin{array}{c}\text { After the third convoy arrives at the disaster point } 8 \text { to unload the needed supplies, it receives the instruction to stand by at the } \\
\text { disaster point } 8\end{array}$ \\
\hline$(8,7)$ & $\begin{array}{r}\text { The situation at the disaster point } 7 \text { is deteriorating; the } \mathrm{t} \\
\text { disaster point } 7 \text { a }\end{array}$ \\
\hline$(8,9)$ & The third convoy remaining vehicles will be distributed to the disaster point 10 (via road node 9) according to the original plan \\
\hline & \\
\hline & se $R_{1}$ will fill up the fourth convoy and distribute it to the 11 disaster areas \\
\hline & \\
\hline 11,7$)$ & uccessfully delivered the cargo to disaster point 7 \\
\hline
\end{tabular}

TABLe 2: Solution matrix for SVNS.

\begin{tabular}{ccccc}
\hline & $C_{1}$ & $C_{2}$ & $C_{3}$ & $C_{4}$ \\
\hline$A_{1}$ & $\langle 0.4,0.4,0.5\rangle$ & $\langle 0.5,0.6,0.7\rangle$ & $\langle 0.4,0.5,0.6\rangle$ & $\langle 0.4,0.5,0.6\rangle$ \\
$A_{2}$ & $\langle 0.5,0.6,0.3\rangle$ & $\langle 0.3,0.5,0.7\rangle$ & $\langle 0.6,0.7,0.4\rangle$ & $\langle 0.7,0.5,0.4\rangle$ \\
$A_{3}$ & $\langle 0.5,0.7,0.4\rangle$ & $\langle 0.4,0.6,0.3\rangle$ & $\langle 0.3,0.5,0.6\rangle$ & $\langle 0.5,0.5,0.6\rangle$ \\
$A_{4}$ & $\langle 0.7,0.5,0.3\rangle$ & $\langle 0.5,0.6,0.3\rangle$ & $\langle 0.7,0.6,0.3\rangle$ & $\langle 0.5,0.7,0.6\rangle$ \\
\hline
\end{tabular}




$$
\begin{aligned}
& E_{1}=0.825, \\
& E_{2}=0.865, \\
& E_{3}=0.850, \\
& E_{4}=0.890 ; \\
& \omega_{1}=0.307, \\
& \omega_{2}=0.237, \\
& \omega_{3}=0.263, \\
& \omega_{4}=0.193 .
\end{aligned}
$$

Step 2. Calculate positive ideal solution $A^{*}$ and negative ideal solution $A^{-*}$.

The scoring function matrix is calculated according to formula (6), as shown in Table 3.

Derived from Table 3 , the positive ideal solution $A^{*}$ and negative ideal solution $A^{-*}$ are as follows:

$$
\begin{aligned}
A^{*}= & (\langle 0.7,0.5,0.3\rangle,\langle 0.5,0.6,0.3\rangle,\langle 0.7,0.6,0.3\rangle, \\
& \langle 0.7,0.5,0.4\rangle), \\
A^{-*}= & (\langle 0.5,0.7,0.4\rangle,\langle 0.3,0.5,0.7\rangle,\langle 0.3,0.5,0.6\rangle, \\
& \langle 0.5,0.7,0.6\rangle) .
\end{aligned}
$$

Step 3. Calculate the distance between the alternatives to the positive ideal solution $A^{*}$ and the negative ideal solution $A^{-*}$.

According to formulas (7)-(9), the distance from each alternative $A_{i}$ to the negative ideal solution $A^{-*}$ are as follows:

$$
\begin{aligned}
& d\left(A_{1}, A^{*}\right)=0.0591, \\
& d\left(A_{2}, A^{*}\right)=0.0304, \\
& d\left(A_{3}, A^{*}\right)=0.0519, \\
& d\left(A_{4}, A^{*}\right)=0.0134 .
\end{aligned}
$$

The distance from each alternative $A_{i}$ to the negative ideal solution $A^{-*}$ are as follows:

$$
\begin{aligned}
& d\left(A_{1}, A^{-*}\right)=0.0079 \\
& d\left(A_{2}, A^{-*}\right)=0.0284 \\
& d\left(A_{3}, A^{-*}\right)=0.0160 \\
& d\left(A_{4}, A^{-*}\right)=0.0624 .
\end{aligned}
$$

Step 4. Calculate the comprehensive distance of each alternative.

Calculated by formula (10),

$$
\begin{aligned}
& G\left(A_{1}\right)=0.118, \\
& G\left(A_{2}\right)=0.483, \\
& G\left(A_{3}\right)=0.236, \\
& G\left(A_{4}\right)=0.823 .
\end{aligned}
$$

TABLE 3: Solution matrix based on the score function.

\begin{tabular}{ccccc}
\hline & $C_{1}$ & $C_{2}$ & $C_{3}$ & $C_{4}$ \\
\hline$A_{1}$ & -0.167 & -0.267 & -0.233 & -0.233 \\
$A_{2}$ & -0.133 & -0.300 & -0.167 & -0.067 \\
$A_{3}$ & -0.200 & -0.167 & -0.267 & -0.200 \\
$A_{4}$ & -0.033 & -0.133 & -0.067 & -0.267 \\
\hline
\end{tabular}

Step 5. Sort $G\left(A_{i}\right)$ from big to small and get the best solution.

$$
G\left(A_{4}\right)>G\left(A_{2}\right)>G\left(A_{3}\right)>G\left(A_{1}\right)
$$

$G\left(A_{4}\right)$ is the max, and choose the path $A_{4}(5 \longrightarrow 7): \mathrm{K} \longrightarrow \mathrm{R} \longrightarrow 11 \longrightarrow 7$.

From the calculation results, it can be seen that the success rate of emergency transfer from the disaster site 11 to the disaster site 7 is the highest, and the distribution time and other restrictive factors may be better met. The key to improve the feasibility of other transfer routes lies in the effective transfer points, such as establishing a material reserve warehouse between the disaster-affected points 1 and 4 , and the material reserve warehouse has enough emergency material reserve. In the emergency distribution and transportation, special circumstances that may be encountered on the way shall be taken into account. In the emergency transfer and distribution from the disaster site 8 to the disaster site 7 , the route shall be correctly selected and traffic jams shall be avoided at the same time, so as to enable the materials to be delivered to the place of demand in the shortest time.

\section{Conclusions}

Emergency transportation requires the effective distribution of materials in the shortest time. However, emergency transportation faces a lot of uncertain information, imprecise information, incomplete information, and inconsistent information, such as the emergency and condition of the event, uncertainty of road condition and traffic time, and material shortage, which makes the decision of emergency distribution more difficult. It is very important to reduce the loss of disaster and adopt scientific and effective methods to deal with information. In this paper, TOPSIS is extended to the environment of a single-valued neutrosophic set to process information. The comparison rule of a single-valued neutrosophic set and the distance measurement method between single-valued neutrosophic sets are used to make the calculation result better, reduce the impact of experts' personal experience and preferences on the final evaluation result, improve the consistency of evaluation result, and make the processing of evaluation data more scientific and reasonable. From the theoretical level, this paper provides a new way to solve the multiattribute decision-making problem under the uncertain information situation, which enriches the research of the single neutrosophic set theory. This proposed method can also be applied in the application of the multiple attribute decision-making with a singlevalued neutrosophic set. 
To examine the effectiveness and highlight the advantages of the proposed method, an emergency operation example is implemented to rank and optimize the alternative transportation routes. In the process of dealing with the disaster, we should use the traditional distribution strategy to implement the emergency distribution mode of transshipment among the disaster-affected points, quickly gather and process the uncertain information of the transshipment point through scientific methods, and output the effective emergency distribution scheme.

\section{Data Availability}

The data used to support the findings of this study are available from the corresponding author upon request.

\section{Conflicts of Interest}

The authors declare that they have no conflicts of interest.

\section{Acknowledgments}

This work was supported in part by the Special Project of Guangxi Humanities and Social Sciences Development Research Center "Scientific Research Engineering Research on High-quality Economic Development Theory of Laterdeveloped Areas" (GZL2019010).

\section{References}

[1] L. Özdamar, E. Ekinci, and B. Küçükyazici, "Emergency logistics planning in natural disasters," Annals of Operations Research, vol. 129, no. 1-4, pp. 217-245, 2004.

[2] T. Hale and C. R. Moberg, "Improving supply chain disaster preparedness," International Journal of Physical Distribution \& Logistics Management, vol. 35, no. 3, pp. 195-207, 2005.

[3] E. D. Miller-Hooks and H. S. Mahmassani, "Least possible time paths in stochastic,time-varying networks," Computers \& Operations Research, vol. 25, no. 12, pp. 1107-1125, 1998.

[4] M.-S. Chang and Y.-L. Tseng, J.-W. Chen, A scenario planning approach for the flood emergency logistics preparation problem under uncertainty," Transportation Research Part E: Logistics and Transportation Review, vol. 43, no. 6, pp. 737754, 2007.

[5] A. K. Rathi, R. L. Church, and R. S. Solanki, "Allocating resources to support a multicommodity flow with time windows," Transportation Research Part E: Logistics and Transportation Review, vol. 28, no. 2, pp. 167-188, 1993.

[6] S.-U. Rahman and D. K. Smith, "Use of location-allocation models in health service development planning in developing nations," European Journal of Operational Research, vol. 123, no. 3, pp. 437-452, 2000.

[7] F. Fiedrich, F. Gehbauer, and U. Rickers, "Optimized resource allocation for emergency response after earthquake disasters," Safety Science, vol. 35, no. 1-3, pp. 41-57, 2000.

[8] W. Yi and L. Özdamar, "A dynamic logistics coordination model for evacuation and support in disaster response activities," European Journal of Operational Research, vol. 179, no. 3, pp. 1177-1193, 2007.

[9] B. Balcik, B. M. Beamon, Facility location in humanitarian relief," International Journal of Logistics Research and Applications, vol. 11, no. 2, pp. 101-121, 2008.
[10] C. G. Rawls and M. A. Turnquist, "Pre-positioning of emergency supplies for disaster response," Transportation Research Part B: Methodological, vol. 44, no. 4, pp. 521-534, 2010.

[11] W. Yi and A. Kumar, "Ant colony optimization for disaster relief operations," Transportation Research Part E: Logistics and Transportation Review, vol. 43, no. 6, pp. 660-672, 2007.

[12] F.-S. Chang, J.-S. Wu, C.-N. Lee, and H.-C. Shen, "Greedysearch-based multi-objective genetic algorithm for emergency logistics scheduling," Expert Systems with Applications, vol. 41, no. 6, pp. 2947-2956, 2014.

[13] Q. L. Yao, "On the characteristics of disaster reduction management in ancient and modern China," Management on Geological Science and Technology, vol. 5, pp. 55-58, 1999.

[14] H. L. Sun, W. Q. Cao, Y. F. Xue, and X. Q. Wang, "Emergency location-routing model with uncertain demands underpath risks," Operations Research and Management Science, vol. 27, no. 7, pp. 37-42, 2018.

[15] J. X. Zhu, J. F. Cai, T. T. Jiang, and X. X. Lin, "Study on the evaluation of emergency logistics network cascading failure invulnerability based on CI-TOPSIS fuzzy multi criteria group decision making tactics," Management Review, vol. 30, no. 9, pp. 229-238, 2018.

[16] F. Smarandache, A Unifying Field in Logics Neutrosophic Logic: Neutrosophy, Neutrosophic Set, Neutrosophic Probability, American Reserch Press, Rehoboth, USA, 1999.

[17] F. Smarandache, "A geometric interpretation of the neutrosophic set-a generalization of the intuitionistic fuzzy set," in Proceedings of the 2011 IEEE International Conference on Granular Computing, pp. 602-606, Kaohsiung, Taiwan, November 2011.

[18] F. Smarandache, "Neutrosophic set-a generalization of the intuitionistic fuzzy set," in Proceedings of the 2006 IEEE International Conference on Granular Computing, Atlanta, Georgia, USA, May 2006.

[19] F. Smarandache, "Introduction to neutrosophic measure, neutrosophic integral, and neutrosophic probability," Computer Science, vol. 22, no. 1, pp. 13-25, 2013.

[20] F. Smarandache, "Neutrosophy, a new branch of philosophy," Multiple-Valued Logic, vol. 8, no. 8, pp. 297-384, 2014.

[21] H. B. Wang, F. Smarandache, Y. Q. Zhang, and R. Sunderraman, "Single valued neutrosophic sets," Multispace and Multistruct, vol. 4, pp. 410-413, 2010.

[22] J. Ye, "A multicriteria decision-making method using aggregation operators for simplified neutrosophic sets," Journal of Intelligent \& Fuzzy Systems, vol. 26, no. 5, pp. 2459-2466, 2014.

[23] J. Ye, "Multicriteria decision-making method using the correlation coefficient under single-valued neutrosophic environment," International Journal of General Systems, vol. 42, no. 4, pp. 386-394, 2013.

[24] S. Pramanik, P. P. Dey, and B. C. Giri, "TOPSIS for single valued neutrosophic soft expert set based multi-attribute decision making problems," Neutrosophic Sets and Systems, vol. 10, pp. 88-95, 2015.

[25] K. Mondal, S. Pramanik, and F. Smarandache, "Rough neutrosophic TOPSIS for multi-attribute group decision making," Neutrosophic Sets and Systems, vol. 13, no. 1, pp. 105-117, 2016.

[26] S. Pramanik, D. Banerjee, and B. C. Giri, "TOPSIS approach for multi attribute group decision making in refined neutrosophic environment," New Trends in Neutrosophic Theory and Applications, pp. 161-174, Pons Editions, Brussels, Belgium, 2016. 
[27] P. P. Dey, S. Pramanik, and B. C. Giri, "TOPSIS for solving multi-attribute decision making problems under Bi-polar neutrosophic environment," New Trends in Neutrosophic Theory and Applications, pp. 65-77, Pons Editions, Brussels, Belgium, 2016.

[28] P. Biswas, S. Pramanik, and B. C. Giri, "TOPSIS method for multi-attribute group decision-making under single-valued neutrosophic environment," Neural Computing and Applications, vol. 27, no. 3, pp. 727-737, 2016.

[29] P. Biswas, S. Pramanik, and B. C. Giri, “TOPSIS strategy for multi-attribute decision making with trapezoidal neutrosophic numbers," Neutrosophic Sets and Systems, vol. 19, pp. 29-39, 2018.

[30] P. Biswas, S. Pramanik, and B. C. Giri, "Neutrosophic TOPSIS with group decision making," Fuzzy Multi-Criteria DecisionMaking Using Neutrosophic Sets, pp. 543-585, Springer, London, UK, 2018.

[31] S. Z. Zeng, D. D. Luo, C. H. Zhang, and X. S. Li, "A correlation-based TOPSIS method for multiple attribute decision making with single-valued neutrosophic information," International Journal of Information Technology \& Decision Making, vol. 19, no. 1, pp. 343-358, 2020.

[32] S. Zeng, S.-M. Chen, and K.-Y. Fan, "Interval-valued intuitionistic fuzzy multiple attribute decision making based on nonlinear programming methodology and TOPSIS method," Information Sciences, vol. 506, pp. 424-442, 2020.

[33] C. Cao, S. Zeng, and D. Luo, "A single-valued neutrosophic linguistic combined weighted distance measure and its application in multiple-attribute group decision-making," Symmetry, vol. 11, no. 2, pp. 275-285, 2019.

[34] S. Zeng and Y. Xiao, "A method based on TOPSIS and distance measures for hesitant fuzzy multiple attribute decision making," Technological and Economic Development of Economy, vol. 24, no. 3, pp. 969-983, 2018.

[35] S. Broumi, M. Talea, A. Bakali, P. K. Singh, and F. Smarandache, "Energy and spectrum analysis of interval valued neutrosophic graph using MATLAB," Neutrosophic Sets and Systems, vol. 24, pp. 46-60, 2019.

[36] S. Broumi, L. H. Son, A. Bakali, M. Talea, F. Smarandache, and G. Selvachandran, "Computing operational matrices in neutrosophic environments: a matlab toolbox," Neutrosophic Sets and Systems, vol. 18, pp. 58-66, 2017.

[37] S. Broumi, A. Bakali, M. Talea, and F. Smarandache, "A matlab toolbox for interval valued neutrosophic matrices for computer applications," Uluslararası Yönetim Bilişim Sistemlerive Bilgisayar Bilimleri Dergisi, vol. 1, no. 1, pp. 1-21, 2017.

[38] S. Topal, S. Broumi, A. Bakali, M. Talea, and F. Smarandache, "A python tool for implementations on bipolar neutrosophic matrices," Neutrosophic Sets and Systems, vol. 28, pp. 138-161, 2019.

[39] P. Biswas, S. Pramanik, and B. C. Giri, "Entropy based grey relational analysis method for multi-attribute decision making under single valued neutrosophic assessments," Neutrosophic Sets and Systems, vol. 2, pp. 102-110, 2014.

[40] P. Majumder and S. K. Samanta, "On similarity and entropy of neutrosophic sets," Journal of Intelligent and Fuzzy Systems, vol. 26, no. 3, pp. 1245-1252, 2014.

[41] C. L. Hwang and K. Yoon, "Multiple attribute decision making: methods and applications: a state-of-the-art survey," Multiple Attribute Decision Making, Springer, Berlin, Germany, 1979.

[42] J. Q. Wang and Z. H. Zhang, "Multi-criteria decision making method with incomplete certain information based on intuitionistic fuzzy number," Control and Decision, vol. 24, pp. 226-230, 2009.

[43] Q. Z. Chai, P. Li, R. Di, and Y. W. Zhang, "TOPSIS method for single-valued neutrosophic sets," Journal of Jiangsu University of Science and Technology (Natural Science Edition), vol. 32, no. 2, pp. 262-265, 2018.

[44] J. Q. Wang and X. E. Li, "TODIM method with multi-valued neutrosophic sets," Control and Decision, vol. 30, no. 6, pp. 1140-1142, 2015. 